\title{
Discrimination learning and extinction in the black rhinoceros (Diceros bicornis)'
}

GARVIN MCCAIN and GEORGE STEPTER, University of Texas at Arlington, Texas 76010

A series of three studies support the possibility of working with large nonlaboratory animals in a zoo setting. Position responses were quite strong and performance curves tended to produce straight lines.

There are numerous animals which have not been subjected to any systematic or even to any sketchy experimental behavioral research. Such is the case with rhinoceroses. Information available is based on scattered field observations, descriptions of behavior in zoos, plus assorted stories of gamekeepers and hunters. This hardly represents adequate information regarding these animals. The present work represents an attempt to develop suitable techniques for working with rhinos and to gather some basic data regarding their discrimination learning. The work is presented in the same sequence as run.

Preliminary Work

A seven-year-old black rhinoceros from the Ft. Worth Zoo was the only $\mathrm{S}$ used for the preliminary work.

The first problem was to determine a proper reinforcer. Carrots, peppermint candy, sugar cubes, cabbage leaves, and white bread were tried; all were eaten readily and with apparent relish. White bread was found to be very suitable and one-half slice, per trial, was sufficient to sustain performance. A rhino will eat up to six large loaves of bread in one session without a noticeable decrease in responsiveness.

Ten sessions of approximately $45 \mathrm{~min}$ each were spent taming the S. Five sessions were spent in allowing the $S$ to become accustomed to the presence of the Es and learning to come when called. Five sessions were spent timing the $S$ on runs from the back to the front of the cage when called and fed. Timed runs did not prove to be a satisfactory measure. The animal is quite sensitive to unusual sounds, movements, or any thing new, so that times were quite variable. Considering the conditions under which the research took place, measures other than timing seem superior.

The third stage of the preliminary work was a black-white discrimination problem. It was determined that the problem was well within the rhino's capacity; also, that this particular rhino often responded on the basis of position. At the beginning of the discrimination problem it was necessary to allow the $\mathrm{S}$ some time to become accustomed to the stimuli since the first exposure to these stimuli led to responses that could reasonably be interpreted as a mixture of fear and belligerence. The preliminary study at $\mathrm{Ft}$. Worth was run in an effort to work out suitable techniques. These data are not presented. although they are compatible with data from the other experiments. In addition, one other study was run with the Dallas rhinos, but is not included here due to space linitations. The results were compatible with those presented in this paper.

\section{FXPERIMENT 1}

This was a simple black-white discrimination problem. Subjects and Apparatus

The Ss in Experiments 1-3 were a male and a female black rhinoceros in the Dallas Zoo. The female is estimated to be nine years old and the male three years old. These rhinos have a large, common enclosure and individual pens. Since the experiments were carried out in the individual pens. only these will be described. The pens were $21 \times 16 \mathrm{ft}$, with a door of heavy bars between the pen and common enclosure. There were three openings between the "I" beams at the front of the pen. Each opening was $40 \mathrm{in}$. long $\times 17 \mathrm{in}$. high.

The stimulus cards were $16 \times 24$ in., one painted black, the other white. During the test period the cards were placed in the openings approximately $8 \mathrm{ft}$ apart.

Procedure

The Ss were fed, tamed, and trained to come when called for approximately $1 \mathrm{~h}$ per day for seven days.

For the discrimination problem in this and succeeding studies, the stimulus cards were changed from side to side according to Gellerman (1939) orders. Each S was given 15 trials per day throughout each experiment. Each trial consisted of El calling the $S$ to the end of the cage away from the cards and feeding one-half slice of bread. E2 then called the $S$ to the end of the cage with the cards. If $S$ responded correctly, E2 hand-fed $1 \frac{1}{2}$ slices of bread. The black card was the correct stimulus for both Ss. A noncorrection procedure was used. During the first three days of training E2 stood behind the correct card on each trial, called $S$ to it, and gave the reward. These days are not included in the data presented in the Results section. After the 3rd day E2 withdrew approximately $8 \mathrm{ft}$ from the guard rail midway between the two cards. When $S$ responded to the proper stimulus E2 advanced and offered the bread. If S's response was incorrect, E2 remained in place, El called $S$ to the other end of the cage and another trial was begun.

Results

One of the most striking aspects of the data in Fig. 1 is that the learning curve could be very well described as approximating two straight lines. Lines shown in Fig. 1 and succeeding figures were fitted using the method of least squares. The Ss started slightly below chance and reached a plateau at slightly under $80 \%$ correct responses. After reaching the plateau the Ss remained close to this level for 12 days or 180 trials.

\section{Apparatus and Procedure}

\section{EXPERIMENT 2}

The apparatus was the same except for the stimulus cards. Each card used had a white background with a black figure centered on it. One figure was an equilateral triangle $25 \mathrm{~cm}$ on each side. The other figure was a circle $9.2 \mathrm{~cm}$ in diameter. The figures themselves were formed of black lines $3 / 4$ in. wide.

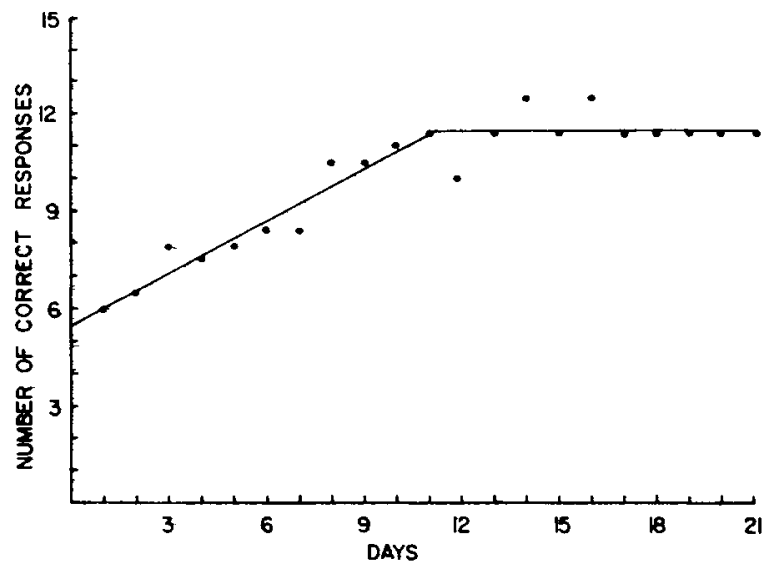

Fig. I. Mean number of correct responses, by days, in the black-white discrimination problem. 


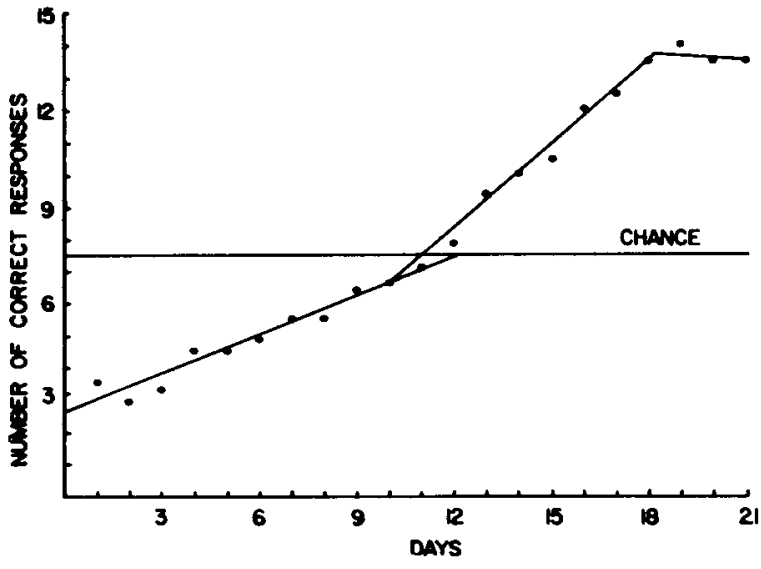

Fig. 2. Mean number of correct responses, by days, in the circle-triangle discrimination problem.

The triangle was reinforced for both Ss. The same procedure used in Experiment 1 was used with the exception of the seven days of taming.

Results

As may be noted from Fig. 2, performance in the first few days was at a very low level; in fact, the first three days are significantly below chance $\left(\chi^{2}=4.26 ; p<.05\right)$. In Fig. 2 the performance curve could be described as three straight lines; one covering the period from the beginning of training to the chance level; the second from chance level to the plateau; the third along the plateau. This plateau very likely represents an end effect due to the approach to the limiting case. There was a highly significant difference in the final level of performance and a chance level $\left(\chi^{2}=9.60 ; p<.002\right)$.

\section{EXPERIMENT 3}

Apparatus and Procedure

The stimulus cards and procedure during the acquisition phase were the same as in Experiment 1. The last 165 trials were an extinction period.

Results

The number of responses to the black stimulus is shown in Fig. 3. Comparison of the acquisition phases of all three experiments indicates that the final plateau tends to be higher

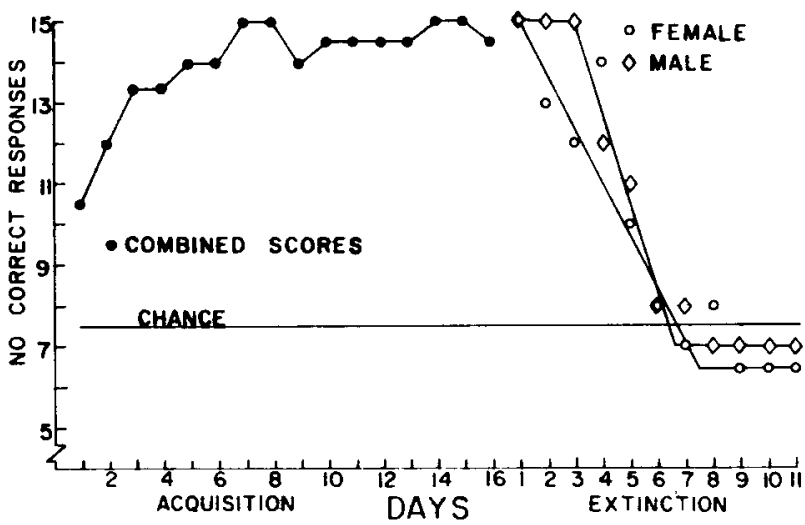

Fig. 3. Correct responses, by days, in the extinction problem. with succeeding experiments $(77,91$, and $97 \%)$. The approach to the plateau is rather rapid in Experiment 3 and the acquisition curve more closely resembles a negatively accelerated curve than do data from any of the earlier studies.

Individual data are shown for the extinction period since there was a considerable difference in the number of trials each $S$ received before evidence of extinction was clear. The male $S$ made 45 responses to the black stimulus card before a response decrement was evident. The female $S$ showed a performance decrement after 15 consecutive nonreinforced trials to the black stimulus card. Considered individually, the extinction curves of each $S$ approximate a straight line. If the individual curves are combined, the result is a curve with a slight positive acceleration. In either case this does not fit the usual rat pattern.

In the first two experiments and the acquisition portion of Experiment 3, there was very little difference in the number of correct responses by the two Ss so that the combined curves are representative.

\section{DISCUSSION}

One result of these studies has been to indicate the possibility of working with large nonlaboratory animals in a zoo setting. The working conditions present problems, but they are not insurmountable.

The change in performance together with the extremely low variability may be as useful as data from brighter and more variable animals. The variability of these animals around their general trend is amazingly low whether plotted together or singly. The conditions under which the acquisition and extinction data were collected makes the low level of variability even more notable.

The response measured in the three experiments during both acquisition and extinction could easily be assumed to have straight-line functions. This is very obviously different from the usual response probability curves found in rat data. It is not clear at this point why the performance curves differ from the usual mammalian curves. The results from Experiment 3 suggest that emotional or experiential factors may be related to the shape of the curve. In any case, the results support the view that expansion of our experimental populations beyond the usual rat and sophomore groups is well worthwile. Other authors (Breland \& Breland, 1961; Hirsch, 1963; Kavanau, 1963) have also questioned assumptions which disregard species differences. Caution in making generalizations across species, in the absence of data, deserves serious consideration.

\section{REFERENCES}

BRELAND, K., \& BRELAND, M. The misbehavior of organisms American Psychologist, 1961, 16, 681.

GELLERMAN, L. W. Chance orders of alternating stimuli in visual discrimination experiments. Journal of Genetic Psychology, 1933, 42, 356-360.

HIRSCH, J. Behavior genetics and individuality understood. Science, $1963,142,1436-1442$.

KAVANAU, J. L. Behavior confinement, adaptation, and compulsory regimes in laboratory studies. Science, 1963, 143, 490. NOTE

1. These studies were made possible through the generous cooperation of the staffs of the Ft. Worth and Dallas Zoos. Lawrence Curtis and Frank Thompson, both formerly with the Ft. Worth Zoo, and Pierre Fountaine and Elvie Turner of the Dallas Zoo, were particularly helpful. Brian McCain and Norman Stepter assisted in collection of the data. A portion of the data was presented at the 1963 American Psychological Association Convention. A256 